\title{
Role of receptor for advanced glycation end products (RAGE) in liver disease
}

\author{
Sho-ichi Yamagishi* and Takanori Matsui
}

\begin{abstract}
Receptor for advanced glycation end products (RAGE) belongs to a immunoglobulin superfamily of cell surface molecules that could bind to a number of ligands such as advanced glycation end products, high-mobility group protein box-1, S-100 calcium-binding protein, and amyloid- $\beta$-protein, inducing a series of signal transduction cascades, and being involved in a variety of cellular function, including inflammation, proliferation, apoptosis, angiogenesis, migration, and fibrosis. RAGE is expressed in hepatic stellate cells and hepatocytes and hepatoma cells. There is accumulating evidence that engagement of RAGE with various ligands elicits oxidative stress generation and subsequently activates the RAGE downstream pathway in the liver, thereby contributing to the development and progression of numerous types of hepatic disorders. These observations suggest that inhibition of the RAGE signaling pathway could be a novel therapeutic target for liver diseases. This article summarizes the pathological role of RAGE in hepatic insulin resistance, steatosis and fibrosis, ischemic and non-ischemic liver injury, and hepatocellular carcinoma growth and metastasis and its therapeutic interventions for these devastating disorders.
\end{abstract}

Keywords: AGES, RAGE, NASH, HCC, Liver injury

\section{Review}

\section{Introduction}

Receptor for advanced glycation end products (AGEs) (RAGE) is a multiligand cell surface receptor that belongs to the immunoglobulin superfamily [1-4]. RAGE is a pattern recognition receptor with a molecular mass of 47 to $55 \mathrm{kDa}$, consisting of an extracellular region made of V1-, C1-, and C2-type immunoglobulin domains, transmembrane-spanning domain, and a short cytosolic tail [1-4]. V1- and C1-type domains are considered as the principal interacting sites for various ligands, whereas cytosolic tail is essential for downstream signaling pathway of RAGE [1-4]. V1- and C1-type domains of RAGE have a net positive charge that might act as an electrostatic trap for negatively charged macromolecules such as AGEs, high-mobility group protein box-1 (HMGB1), S-100 calcium-binding protein, and amyloid$\beta$-protein [1-4].

RAGE is found in an oligomeric or preassembled state within the plasma membrane [1-4]. RAGE expression is

\footnotetext{
* Correspondence: shoichi@med.kurume-u.ac.jp

Department of Pathophysiology and Therapeutics of Diabetic Vascular

Complications, Kurume University School of Medicine, 67 Asahi-machi, Kurume
} 830-0011, Japan usually low in the majority of healthy adult tissues, but its levels are elevated under pathological conditions such as diabetes, cardiovascular disease, Alzheimer's disease, and cancer [4-7]. Multimeric ligands could stabilize the assemblies of RAGE and shift the equilibrium to larger oligomers [1-4]. Moreover, engagement of RAGE with RAGE ligands increases expression of RAGE itself in a variety of cells [4-7]. These positive feedback loops could partly explain why RAGE-ligands interaction could lead to sustained activation of the RAGE downstream pathway.

RAGE activation by various ligands have been reported to increase oxidative stress generation and subsequently evoke inflammatory, proliferative, angiogenic, fibrotic, thrombogenic, and apoptotic reactions in numerous cell types via activation of diverse intracellular signaling pathways such as nuclear factor- $\mathrm{k} B(\mathrm{NF}-\mathrm{k} \mathrm{B})$, mitogen-activated protein kinase (MAPK), Janus kinase-signal transducers and activators of transcription (JAK-STAT), and phosphoinositol 3 kinase [8-10]. RAGE is expressed in hepatic stellate cells and hepatocytes and hepatoma cells [11]. There is accumulating evidence that activation of RAGE signaling pathways in the liver could contribute to the development and progression of numerous types of hepatic disorders [11,12]. These observations suggest that inhibition of the RAGE downstream 
pathway could be a novel therapeutic target for various liver diseases. This article summarizes the pathological role of RAGE in hepatic insulin resistance, steatosis and fibrosis, ischemic or non-ischemic liver injury, and hepatocellular carcinoma (HCC) growth and metastasis and its therapeutic interventions for these devastating disorders.

In the present review, literature searches were undertaken in Medline by the PubMed interface. Non-English language articles were excluded. Key words (RAGE) and (review or liver or hepatic) have been used to select the articles.

\section{Hepatic insulin resistance, steatosis, and fibrosis}

1) Hepatic insulin resistance Non-alcoholic fatty liver (NAFL) is the most common chronic liver disease in the world [13-16]. NAFL is characterized by hepatic steatosis in the absence of significant alcohol intake or other known liver diseases. NAFL includes a wide spectrum of liver diseases, ranging from fatty liver, a benign and nonprogressive condition, to non-alcoholic steatohepatitis (NASH), a potentially progressive disease that may cause cirrhosis, liver failure, and HCC [13-16]. NASH is considered the hepatic manifestation of the metabolic syndrome and is associated with central obesity, insulin resistance, diabetes, essential hypertension, and dyslipidemia $[17,18]$.

We have previously shown that serum levels of AGEs are elevated under oxidative stress, inflammatory, and/ or diabetic conditions and correlated with insulin resistance and decreased adiponectin levels, thereby being one of the useful biomarkers for differentiating NASH from simple steatosis [19-24]. Further, activation of RAGE downstream pathway by AGEs evokes inflammatory reactions and impairs insulin signaling in Hep3B hepatoma cells by stimulating c-Jun $\mathrm{NH} 2$-terminal kinase (JNK)- and IKB kinase-dependent serine phosphorylation of insulin receptor substrate-1 via Rac-1 activation [25-27]. Combination therapy with nateglinide, a rapid-onset/short-duration insulinotropic agent and telmisartan, an angiotensin II type 1 receptor blocker with partial agonistic activity of peroxisome proliferator-activated receptor- $\gamma$ (PPAR $\gamma)$, improves hepatic insulin resistance in Zucker fatty rats by suppressing the AGE-RAGE axis as well [28]. These observations suggest the involvement of AGE-RAGE axis in inflammation and insulin resistance in the liver.

2) Hepatic steatosis

High AGE-containing methionine choline-deficient (MCD) diet increased AGE contents, lipid peroxidation product, 4-hydroxynonenal levels, and NADPH oxidase- driven superoxide generation in the liver of Sprague Dawley (SD) rats compared to SD rats with MCD diet alone, which were associated with severity of steatohepatitis and hepatic fibrosis in these animals [29]. Furthermore, AGEs significantly increased reactive oxygen species (ROS) production, RAGE, monocyte chemoattractant protein-1 (MCP-1), interleukin-6 (IL-6), and $\alpha$-smooth muscle cell actin expression in hepatic stellate cells (HSCs) derived from MCD diet-fed rats [29]. In addition, Gaen et al. recently reported that carboxymethyllysine (CML) accumulation in the liver of obese individuals was associated with hepatic pro-inflammatory gene expression as well as grade of steatosis and steatohepatitis [30]. They also found that fatty acids could stimulate CML accumulation in hepatocytes and subsequently elicit inflammatory reactions via RAGE induction [30]. Lack of galectin-3, a scavenging receptor for AGEs, has been shown to progress the NAFL disease in mice, which was also associated with enhanced hepatic accumulation of AGEs and RAGE expression [31,32]. These findings suggest that dietary glycotoxins and/or lipid peroxidation-induced AGE accumulation in the liver might promote the progression of NAFL to NASH by enhancing the RAGE-mediated inflammatory reactions.

\section{3) Hepatic fibrosis}

HSCs are the main extracellular matrix-producing cells in the liver and thus play a pivotal role in liver fibrosis [33]. Fehrenbach et al. showed that expression of RAGE was up-regulated during the process of transdifferentiation of HSCs to myofibroblasts (MFB) and transforming growth factor- $\beta 1$ (TGF- $\beta 1$ ) increased RAGE and $\alpha$-smooth muscle actin levels at filopodial membranes of MFB, thus suggesting a role of TGF- $\beta 1-R A G E$ axis in the spreading and migration of activated HSCs. They also showed that ligand activation of RAGE increased ROS formation and subsequently induced MAPK and NF- $\mathrm{KB}$ signaling pathways in HSCs [33]. Furthermore, we have found that AGE-RAGE interaction induces proliferative, inflammatory, and fibrotic reactions in HSCs by stimulating TGF- $\beta 1$, MCP- 1 , collagen type I alpha2, and $\alpha$-smooth muscle actin expression via NADPH oxidase-derived ROS generation [34]. ROS generation in HSCs evoked by the AGE-RAGE axis is blocked by an inhibitor of Rac-1, a component of NADPH oxidase, or p47phox silencing [35]. These observations suggest that RAGE-mediated, NADPH oxidase-derived ROS could contribute to hepatic fibrosis via the activation of HSCs.

Curcumin, a main curcuminoid present in turmeric, a popular Indian spice, inhibited AGE-induced 
RAGE expression in HSCs by increasing PPARy activity and stimulating de novo synthesis of glutathione, which could lead to the suppression of oxidative stress generation, inflammation, and HSCs activation [36]. Curcumin was also shown to eliminate the deleterious effects of AGE-RAGE axis on HSCs by inducing gene expression of AGE receptor-1, a responsible receptor for detoxification and clearance of AGEs, partly via interruption of leptin signaling and activation of transcription factor NF-E2 p45-related factor $2[37,38]$. We have previously shown that (1) pigment epithelium-derived factor (PEDF), a glycoprotein with anti-oxidative, anti-inflammatory, and PPAR $\gamma$-stimulating properties blocks the AGE- or IL-6-induced hepatic inflammation and (2) serum PEDF levels are independently associated with procollagen type III N-terminal peptide, a marker of hepatic fibrosis in patients with NAFL as a counter system against insulin resistance-related metabolic derangements [39-44]. Stimulation of PPAR $\gamma$ may be a therapeutic target for preventing the HSCs activation.

In normal rats, chronic AGEs administration induced significant increases in $\alpha$-smooth muscle actin levels, but did not induce fibrosis or biochemical evidence of liver injury [45]. However, injection of AGEs to rats following bile duct ligation significantly increased hepatic fibrosis, which was in association with oxidative stress and RAGE overexpression in the liver [45]. Furthermore, RAGE gene-silencing therapy decreased serum levels of inflammatory cytokines, reduced hepatic levels of $\alpha$-smooth muscle actin and collagen I, markers of HSCs activation, and improved inflammatory activity grade and fibrosis stage of CCl4induced liver injury in rats [46]. Kao et al. reported the involvement of HMGB1 released from damaged hepatocytes and its interaction with RAGE in the pathogenesis of HSCs activation and liver fibrosis [47]. Carotenoids and polyphenols present in peach-derived products have been shown to attenuate the $\mathrm{CCl} 4$ induced oxidative stress and liver damage by suppressing RAGE expression [48].

\section{Ischemic or non-ischemic liver injury}

Ischemic liver disease Hepatic ischemia/reperfusion (I/R) injury associated with liver transplantation and hepatic resection is characterized by hepatocyte damage and enhanced inflammatory reactions [49]. Administration of soluble form of RAGE (sRAGE) has been reported to increase survival of mice after hepatic $I / R$ injury by suppressing the RAGE downstream pathway, which was associated with decreased cell death and necrosis of hepatocytes as well as increased proliferative activity of liver cells [49]. MAPK, JNK, and JAK-STAT were activated in I/R-injured liver, while NF- $\mathrm{kB}$ was suppressed. All of these changes were ameliorated by the treatment with sRAGE, in parallel with increased expression of pro-regenerative cytokine [49]. In addition, RAGEmediated increased expression of early growth response-1 (Egr-1), an inducible zinc finger transcription factor activated in response to cell stress, was involved in enhanced inflammatory reactions in the I/R-injured liver [50]. Losartan, a blocker of angiotensin II type 1 receptor, inhibited the I/R injury-induced hepatocyte apoptosis and inflammation by suppressing the RAGE expression and subsequent activation of Egr-1 via PPAR $\gamma$ activation [51]. These findings suggest that RAGE could modulate hepatic I/R injury, at least in part by activation of key signaling pathways linked to pro-inflammatory and cell deathpromoting responses.

\section{Non-ischemic liver disease}

Uncoupling protein-2 (UCP2) knockout mice showed higher malondialdehyde levels and reduced glutathione/ glutathione disulfide ratios as well as significantly higher hepatic levels of AGEs and RAGE compared with normal mice [52]. Galactosamine/lipopolysaccharide (G/L)induced liver injury was enhanced in UCP2 knockout mice, which was associated with increased AGEs and RAGE levels in the liver [52]. Further, aging accelerated the harmful effects of UCP2 deficiency on AGE-RAGE axis and G/L-induced liver injury by suppressing hepatic activity of glyoxalase-I, a detoxifying enzyme for methyglyoxal, one of the precursors of AGEs [53]. sRAGE treatment has been found to significantly diminish liver damage and increased survival particularly in both young and old UCP2 knockout mice [52,53]. These observations suggest that mitochondrial dysfunction-associated oxidative stress could activate hepatic AGE-RAGE axis, leading to augmentation of inflammation-induced liver injury. Anti-RAGE antibody therapy inhibited the G/L-induced acute liver injury in senescence-accelerated-prone mice [54]. Sinusoidal perfusion failure and inflammation in the livers exposed to G/L were also suppressed by the treatment with anti-RAGE antibody [55]. These findings could further support the clinical relevance of RAGE blockade for the treatment of endotoxemic liver damage.

RAGE is up-regulated in liver remnants selectively after massive (85\%) versus partial (70\%) hepatectomy, principally in mononuclear phagocyte-derived dendritic cells [56]. Furthermore, blockade of RAGE, using pharmacological antagonists or transgenic mice in which a signaling-deficient RAGE mutant is expressed in cells of mononuclear phagocyte lineage, significantly increases survival after massive liver resection [56]. RAGE inhibition induced NF- $\mathrm{kB}$ activation and resultantly enhanced expression of regeneration-promoting cytokines in the massively injured liver [56]. sRAGE treatment also 
decreased hepatic necrosis and inflammatory and oxidative stress reactions and increased survival of mice with acetaminophen-induced liver injury [57]. Blockade of RAGE may improve survival of mice with extensive hepatectomy by restoring adaptive mechanisms triggered by Myd88 signaling pathways [58].

\section{HCC}

RAGE was expressed in human HCC cell line, Hep3B and HepG2 cells, whereas AGEs increased vascular endothelial growth factor (VEGF) expression in these cell types $[59,60]$. Furthermore, AGE-treated conditioned medium significantly increased proliferation, migration, and tube formation of endothelial cells (ECs), thus suggesting that AGE-RAGE signaling could enhance the angiogenic potential of HCC cells by up-regulating VEGF expression [59]. AGEs have been shown to increase the growth of $\mathrm{HuH7}$, other type of $\mathrm{HCC}$ cell line as well [60]. MK615, an extract from Japanese apricot was reported to inhibit the AGEs-induced proliferation of HuH7 by suppressing RAGE expression [60]. Orally administered high-AGE beverage induced hepatic VEGF expression and AGE accumulation in rats, suggesting a pathological role of dietary AGEs for the progression of HCC [61].

We have previously shown that AGE-RAGE interactionmediated, NADPH oxidase-induced ROS generation stimulates proliferation and tube formation of ECs, the key steps of tumor angiogenesis, through VEGF expression via transcriptional activation of NF- $\mathrm{kB}$ and activator protein-1 [62-66]. Furthermore, activation of the AGE-RAGE axis also evokes inflammatory and thrombogenic reactions in ECs by inducing MCP-1, intercellular adhesion molecule1 , and plasminogen activator inhibitor-1 expression via ROS generation [67-73]. Several lines of evidence implicate VEGF as the key factor involved in tumor growth and metastasis [74]. VEGF expression levels are associated with angiogenesis and macrophage infiltration, the extent of which being correlated with various tumor prognoses [75-79]. So, the AGE-RAGE interaction could stimulate tumor-associated angiogenesis and macrophage infiltration by inducing VEGF expression and its related inflammatory reactions, thereby promoting tumor growth and metastasis. In addition, the AGE-RAGE-evoked thrombogenic reactions could cause ischemia and hypoxia within the tumor environments and trigger VEGF expression again, thus further augmenting tumor angiogenesis and inflammation. Further, hypoxia has been known to stimulate brisk generation of AGEs by ECs and subsequently activates the RAGE downstream pathway, which could induce upregulation of Egr-1, thereby causing inflammatory and thrombotic reactions within the hypoxic areas of tumors [80]. Therefore, these positive feedback loops between AGE-RAGE axis and hypoxia might further potentiate tumor-associated angiogenesis and inflammation, being involved in HCC growth and expansion.
HCC lines resistant to hypoxia were found to have higher levels of RAGE expression, and RAGE overexpression showed significantly prolonged survival under hypoxia [81]. Furthermore, cytoplasmic expression of RAGE was correlated with poorly differentiated HCC, and RAGE was an independent predictor for both overall survival and diseasefree survival in patients with HCC after hepatectomy [82].

Knockdown of RAGE by small interfering RNAs inhibited proliferation of HuH7 cells and induced G1 arrest of this cell type, whereas HMGB1, one of the ligands for RAGE, exerted opposite effects on HuH7 cells [83]. HMGB1-RAGE-evoked NF- $k B$ activation has been shown to promote the invasiveness of $\mathrm{HCC}$ via activation of heat shock protein 70 [84]. Ethyl pyruvate induced apoptosis and cell cycle arrest in G phase in HCC by suppressing the HMGB1-RAGE-induced Akt activation and matrix metallopeptidase-9 expression [85]. Moreover, in hypoxic HCC cells, HMGB1 activates the RAGE-signaling pathway to induce caspase-1 activity with subsequent production of multiple inflammatory mediators, which, in turn, could enhance the invasion and metastasis of HCC [86].

\section{Conclusions}

As discussed here, there is accumulating evidence that RAGE could play a pathological role in numerous liver diseases via increased oxidative stress generation and inflammatory reactions (Figure 1). RAGE ligands up-regulate RAGE expression itself in the liver, further potentiating the harmful effects of RAGE ligands on hepatic insulin resistance, steatosis, and fibrosis, ischemic and nonischemic liver disease, and growth and metastasis of HCC, especially in elderly persons or patients with metabolic disorders. Blockade of the RAGE downstream pathway, knockdown of RAGE expression, or restriction of dietary AGEs might be a novel therapeutic target for these devastating hepatic disorders.

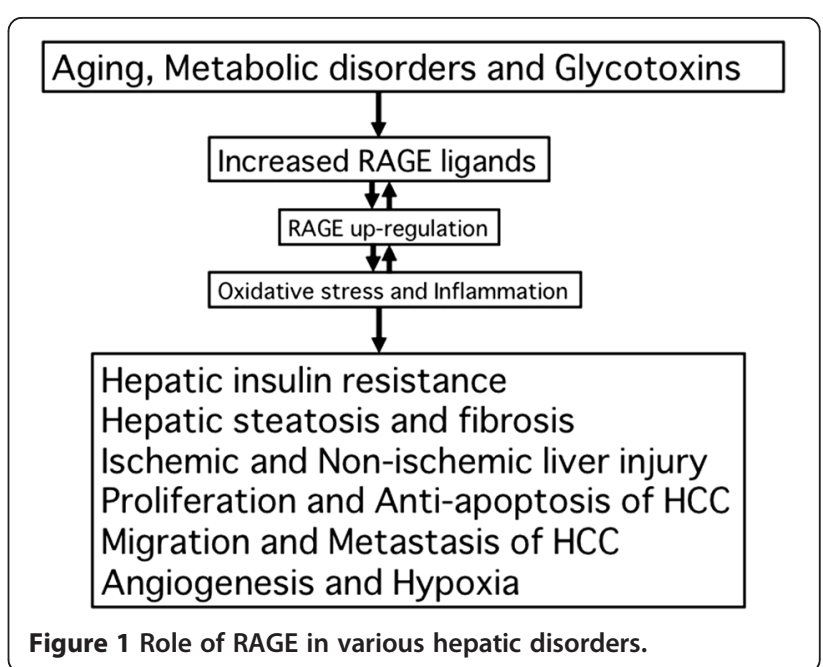




\section{Competing interests}

The authors declare that they have no competing interests.

\section{Authors' contributions}

SY mainly contributed to the present paper, conceptualized and designed the paper, drafted the manuscript, and took responsibility for the integrity of the data and the accuracy of the data analysis. TM made the critical review for intellectual content. Both authors approved the final manuscript.

\section{Acknowledgements}

This study was supported in part by Grants-in-Aid for Scientific Research (B) (Grant Number 25293127) from the Ministry of Education, Culture, Sports, Science and Technology, Japan (to S.Y.).

Received: 21 November 2014 Accepted: 22 January 2015

Published online: 11 February 2015

\section{References}

1. Ramasamy R, Yan SF, Schmidt AM. The diverse ligand repertoire of the receptor for advanced glycation endproducts and pathways to the complications of diabetes. Vascul Pharmacol. 2012;57:160-7.

2. Yamagishi S, Matsui T. Soluble form of a receptor for advanced glycation end products (sRAGE) as a biomarker. Front Biosci (Elite Ed). 2010;2:1184-95.

3. Fritz G. RAGE: a single receptor fits multiple ligands. Trends Biochem Sci. 2011;36:625-32.

4. Sorci G, Riuzzi F, Giambanco I, Donato R. RAGE in tissue homeostasis, repair and regeneration. Biochim Biophys Acta. 2013;1833:101-9.

5. Yamagishi S, Nakamura K, Matsui T, Noda Y, Imaizumi T. Receptor for advanced glycation end products (RAGE): a novel therapeutic target for diabetic vascular complication. Curr Pharm Des. 2008;14:487-95.

6. Abe R, Yamagishi S. AGE-RAGE system and carcinogenesis. Curr Pharm Des. 2008;14:940-5.

7. Takeuchi M, Yamagishi S. Involvement of toxic AGEs (TAGE) in the pathogenesis of diabetic vascular complications and Alzheimer's disease. J Alzheimers Dis. 2009;16:845-58.

8. Daffu G, Del Pozo CH, O'Shea KM, Ananthakrishnan R, Ramasamy R, Schmidt AM. Radical roles for RAGE in the pathogenesis of oxidative stress in cardiovascular diseases and beyond. Int J Mol Sci. 2013;14:19891-910.

9. Cohen Jr MM. Perspectives on RAGE signaling and its role in cardiovascular disease. Am J Med Genet A. 2013;161A:2750-5.

10. Ott C, Jacobs K, Haucke E, Navarrete Santos A, Grune T, Simm A. Role of advanced glycation end products in cellular signaling. Redox Biol. 2014;2:411-29.

11. Hyogo H, Yamagishi S. Advanced glycation end products (AGES) and their involvement in liver disease. Curr Pharm Des. 2008;14:969-72.

12. Basta G, Navarra T, De Simone P, Del Turco S, Gastaldelli A, Filipponi F. What is the role of the receptor for advanced glycation end products-ligand axis in liver injury? Liver Transpl. 2011;17:633-40.

13. Teli MR, James OF, Burt AD, Bennett MK, Day CP. The natural history of nonalcoholic fatty liver: a follow-up study. Hepatology. 1995;22:1714-9.

14. Dam-Larsen S, Franzmann M, Andersen IB, Christoffersen P, Jensen LB, Sørensen $\mathrm{Tl}$, et al. Long term prognosis of fatty liver: risk of chronic liver disease and death. Gut. 2004;53:750-5.

15. Matteoni CA, Younossi ZM, Gramlich T, Boparai N, Liu YC, McCullough AJ. Nonalcoholic fatty liver disease: a spectrum of clinical and pathological severity. Gastroenterology. 1999;116:1413-9.

16. Hyogo H, Chayama K, Yamagishi S. Nonalcoholic fatty liver disease and cardiovascular disease. Curr Pharm Des. 2014;20:2403-11.

17. Chitturi S, Abeygunasekera S, Farrell GC, Holmes-Walker J, Hui JM, Fung C, et al. NASH and insulin resistance: insulin hypersecretion and specific association with the insulin resistance syndrome. Hepatology. 2002;35:373-9.

18. Marchesini G, Brizi M, Bianchi G, Tomassetti S, Bugianesi E, Lenzi M, et al. Nonalcoholic fatty liver disease: a feature of the metabolic syndrome. Diabetes. 2001;50:1844-50.

19. Jinnouchi Y, Yamagishi S, Takeuchi M, Ishida S, Jinnouchi Y, Jinnouchi J, et al. Atorvastatin decreases serum levels of advanced glycation end products (AGEs) in patients with type 2 diabetes. Clin Exp Med. 2006;6:191-3.

20. Tahara N, Yamagishi S, Matsui T, Takeuchi M, Nitta Y, Kodama N, et al. Serum levels of advanced glycation end products (AGEs) are independent correlates of insulin resistance in nondiabetic subjects. Cardiovasc Ther. 2012;30:42-8.
21. Tahara N, Imaizumi T, Takeuchi M, Yamagishi SI. Insulin resistance is an independent correlate of high serum levels of advanced glycation end products (AGEs) and low testosterone in non-diabetic men. Oxid Med Cell Longev. 2010;3:262-5.

22. Tahara N, Yamagishi S, Tahara A, Ishibashi M, Hayabuchi N, Takeuchi M, et al. Adiponectin is inversely associated with ratio of serum levels of AGEs to sRAGE and vascular inflammation. Int J Cardiol. 2012;158:461-2.

23. Hyogo H, Yamagishi S, Iwamoto K, Arihiro K, Takeuchi M, Sato T, et al. Elevated levels of serum advanced glycation end products in patients with non-alcoholic steatohepatitis. J Gastroenterol Hepatol. 2007;22:1112-9.

24. Kimura Y, Hyogo H, Yamagishi S, Takeuchi M, Ishitobi T, Nabeshima Y, et al. Atorvastatin decreases serum levels of advanced glycation endproducts (AGEs) in nonalcoholic steatohepatitis (NASH) patients with dyslipidemia: clinical usefulness of AGEs as a biomarker for the attenuation of NASH. J Gastroenterol. 2010;45:750-7.

25. Yoshida T, Yamagishi S, Nakamura K, Matsui T, Imaizumi T, Takeuchi M, et al. Telmisartan inhibits AGE-induced C-reactive protein production through downregulation of the receptor for AGE via peroxisome proliferatoractivated receptor-gamma activation. Diabetologia. 2006;49:3094-9.

26. Yoshida T, Yamagishi S, Matsui T, Nakamura K, Ueno T, Takeuchi M, et al. Telmisartan, an angiotensin II type 1 receptor blocker, inhibits advanced glycation end-product (AGE)-elicited hepatic insulin resistance via peroxisome proliferator-activated receptor-gamma activation. J Int Med Res. 2008;36:237-43.

27. Yoshida T, Yamagishi S, Nakamura K, Matsui T, Imaizumi T, Takeuchi M, et al. Pigment epithelium-derived factor (PEDF) ameliorates advanced glycation end product (AGE)-induced hepatic insulin resistance in vitro by suppressing Rac-1 activation. Horm Metab Res. 2008;40:620-5.

28. Miura K, Kitahara Y, Kajioka T, Takeuchi M, Yamagishi S. Combination therapy with nateglinide and telmisartan ameliorates insulin resistance in Zucker fatty rats by suppressing advanced glycation end product receptor axis. Horm Metab Res. 2011;43:226-8.

29. Leung C, Herath CB, Jia Z, Goodwin M, Mak KY, Watt MJ, et al. Dietary glycotoxins exacerbate progression of experimental fatty liver disease. J Hepatol. 2014;60:832-8.

30. Gaens KH, Niessen PM, Rensen SS, Buurman WA, Greve JW, Driessen A, et al. Endogenous formation of $\mathrm{N} \varepsilon$-(carboxymethyl)lysine is increased in fatty livers and induces inflammatory markers in an in vitro model of hepatic steatosis. J Hepatol. 2012;56:647-55.

31. Nomoto K, Tsuneyama K, Abdel Aziz HO, Takahashi H, Murai Y, Cui ZG, et al. Disrupted galectin-3 causes non-alcoholic fatty liver disease in male mice. J Pathol. 2006;210:469-77.

32. Pugliese $G$, lacobini C, Pesce CM, Menini S: Galectin-3: an emerging all-out player in metabolic disorders and their complications. Glycobiology 2014 (in press).

33. Fehrenbach $H$, Weiskirchen $R$, Kasper M, Gressner AM. Up-regulated expression of the receptor for advanced glycation end products in cultured rat hepatic stellate cells during transdifferentiation to myofibroblasts. Hepatology. 2001;34:943-52.

34. Iwamoto K, Kanno K, Hyogo H, Yamagishi S, Takeuchi M, Tazuma S, et al. Advanced glycation end products enhance the proliferation and activation of hepatic stellate cells. J Gastroenterol. 2008;43:298-304.

35. Guimarães EL, Empsen C, Geerts A, Van Grunsven LA. Advanced glycation end products induce production of reactive oxygen species via the activation of NADPH oxidase in murine hepatic stellate cells. J Hepatol. 2010;52:389-97.

36. Lin J, Tang Y, Kang Q, Feng Y, Chen A. Curcumin inhibits gene expression of receptor for advanced glycation end-products (RAGE) in hepatic stellate cells in vitro by elevating PPARY activity and attenuating oxidative stress. Br J Pharmacol. 2012;166:2212-27.

37. Lin J, Tang Y, Kang Q, Chen A. Curcumin eliminates the inhibitory effect of advanced glycation end-products (AGEs) on gene expression of AGE receptor-1 in hepatic stellate cells in vitro. Lab Invest. 2012;92:827-41.

38. Tang Y, Chen A. Curcumin eliminates the effect of advanced glycation endproducts (AGEs) on the divergent regulation of gene expression of receptors of AGEs by interrupting leptin signaling. Lab Invest. 2014;94:503-16.

39. Yoshida T, Yamagishi S, Nakamura K, Matsui T, Imaizumi T, Takeuchi M, et al. Pigment epithelium-derived factor (PEDF) inhibits advanced glycation end product (AGE)-induced C-reactive protein expression in hepatoma cells by suppressing Rac-1 activation. FEBS Lett. 2006;580:2788-96.

40. Yoshida T, Yamagishi S, Nakamura K, Matsui T, Imaizumi T, Inoue H, et al. Pigment epithelium-derived factor (PEDF) blocks the interleukin- 6 signaling to C-reactive protein expression in Hep3B cells by suppressing Rac-1 activation. Life Sci. 2006;79:1981-7. 
41. Hyogo H, Yamagishi S, Maeda S, Kimura Y, Ishitobi T, Chayama K. Serum levels of pigment epithelium-derived factor (PEDF) are independently associated with procollagen III N-terminal peptide levels in patients with nonalcoholic fatty liver disease. Clin Biochem. 2012;45:1554-7.

42. Ishibashi Y, Matsui T, Ohta K, Tanoue R, Takeuchi M, Asanuma K, et al. PEDF inhibits AGE-induced podocyte apoptosis via PPAR-gamma activation. Microvasc Res. 2013;85:54-8.

43. Yamagishi S, Matsui T. Pigment epithelium-derived factor (PEDF) and cardiometabolic disorders. Curr Pharm Des. 2014;20:2377-86.

44. Matsui T, Nishino Y, Ojima A, Maeda S, Tahara N, Yamagishi S. Pigment epithelium-derived factor improves metabolic derangements and ameliorates dysregulation of adipocytokines in obese type 2 diabetic rats. Am J Pathol. 2014;184:1094-103.

45. Goodwin M, Herath C, Jia Z, Leung C, Coughlan MT, Forbes J, et al. Advanced glycation end products augment experimental hepatic fibrosis. J Gastroenterol Hepatol. 2013;28:369-76.

46. Cai XG, Xia JR, Li WD, Lu FL, Liu J, Lu Q, et al. Anti-fibrotic effects of specificsiRNA targeting of the receptor for advanced glycation end products in a rat model of experimental hepatic fibrosis. Mol Med Rep. 2014;10:306-14.

47. Kao YH, Lin YC, Tsai MS, Sun CK, Yuan SS, Chang CY, et al. Involvement of the nuclear high mobility group B1 peptides released from injured hepatocytes in murine hepatic fibrogenesis. Biochim Biophys Acta. 2014;1842:1720-32.

48. Gasparotto J, Somensi N, Bortolin RC, Girardi CS, Kunzler A, Rabelo TK, Schnorr CE, Moresco KS, Bassani VL, Yatsu FK, et al:: Preventive supplementation with fresh and preserved peach attenuates CCl4-induced oxidative stress, inflammation and tissue damage. J Nutr Biochem 2014, doi:10.1016/j. jnutbio.2014.07.004

49. Zeng S, Feirt N, Goldstein M, Guarrera J, Ippagunta N, Ekong U, et al. Blockade of receptor for advanced glycation end product (RAGE) attenuates ischemia and reperfusion injury to the liver in mice. Hepatology. 2004;39:422-32.

50. Zeng S, Dun H, Ippagunta N, Rosario R, Zhang QY, Lefkowitch J, et al. Receptor for advanced glycation end product (RAGE)-dependent modulation of early growth response- 1 in hepatic ischemia/reperfusion injury. J Hepatol. 2009;50:929-36.

51. Koh EJ, Yoon SJ, Lee SM. Losartan protects liver against ischaemia/ reperfusion injury through PPAR- $\gamma$ activation and receptor for advanced glycation end-products down-regulation. Br J Pharmacol. 2013;169:1404-16.

52. Kuhla A, Hettwer C, Menger MD, Vollmar B. Oxidative stress-associated rise of hepatic protein glycation increases inflammatory liver injury in uncoupling protein-2 deficient mice. Lab Invest. 2010;90:1189-98.

53. Kuhla A, Trieglaff C, Vollmar B. Role of age and uncoupling protein-2 in oxidative stress, RAGE/AGE interaction and inflammatory liver injury. Exp Gerontol. 2011;46:868-76.

54. Kuhla A, Hauke M, Sempert K, Vollmar B, Zechner D. Senescence-dependent impact of anti-RAGE antibody on endotoxemic liver failure. Age (Dordr). 2013;35:2153-63.

55. Kuhla A, Norden J, Abshagen K, Menger MD, Vollmar B. RAGE blockade and hepatic microcirculation in experimental endotoxaemic liver failure. $\mathrm{Br} J$ Surg. 2013;100:1229-39.

56. Cataldegirmen G, Zeng S, Feirt N, Ippagunta N, Dun H, Qu W, et al. RAGE limits regeneration after massive liver injury by coordinated suppression of TNF-alpha and NF-kappaB. J Exp Med. 2005;201:473-84.

57. Ekong U, Zeng S, Dun H, Feirt N, Guo J, Ippagunta N, et al. Blockade of the receptor for advanced glycation end products attenuates acetaminophen-induced hepatotoxicity in mice. J Gastroenterol Hepatol. 2006:21:682-8.

58. Zeng S, Zhang QY, Huang J, Vedantham S, Rosario R, Ananthakrishnan R, et al. Opposing roles of RAGE and Myd88 signaling in extensive liver resection. FASEB J. 2012;26:882-93.

59. Takino J, Yamagishi S, Takeuchi M. Glycer-AGEs-RAGE signaling enhances the angiogenic potential of hepatocellular carcinoma by upregulating VEGF expression. World J Gastroenterol. 2012;18:1781-8.

60. Sakuraoka Y, Sawada T, Okada T, Shiraki T, Miura Y, Hiraishi K, et al. MK615 decreases RAGE expression and inhibits TAGE-induced proliferation in hepatocellular carcinoma cells. World J Gastroenterol. 2010;16:5334-41.

61. Sato T, Wu X, Shimogaito N, Takino J, Yamagishi S, Takeuchi M. Effects of high-AGE beverage on RAGE and VEGF expressions in the liver and kidneys. Eur J Nutr. 2009;48:6-11.
62. Okamoto T, Yamagishi S, Inagaki Y, Amano S, Koga K, Abe R, et al. Angiogenesis induced by advanced glycation end products and its prevention by cerivastatin. FASEB J. 2002;16:1928-30.

63. Yamagishi S, Matsui T, Nakamura K, Inoue H, Takeuchi M, Ueda S, et al. Olmesartan blocks advanced glycation end products (AGEs)-induced angiogenesis in vitro by suppressing receptor for AGEs (RAGE) expression. Microvasc Res. 2008;75:130-4.

64. Yamagishi SI, Nakamura K, Matsui T, Yoshida T, Takeuchi M, Imaizumi T. Pigment epithelium-derived factor (PEDF) blocks advanced glycation end product (AGE)-induced angiogenesis in vitro. Horm Metab Res. 2007;39:233-5.

65. Yamagishi S, Nakamura K, Matsui T, Inagaki Y, Takenaka K, Jinnouchi Y, et al. Pigment epithelium-derived factor inhibits advanced glycation end product-induced retinal vascular hyperpermeability by blocking reactive oxygen species-mediated vascular endothelial growth factor expression. J Biol Chem. 2006;281:20213-20.

66. Niiya Y, Abumiya T, Yamagishi S, Takino J, Takeuchi M. Advanced glycation end products increase permeability of brain microvascular endothelial cells through reactive oxygen species-induced vascular endothelial growth factor expression. J Stroke Cerebrovasc Dis. 2012;21:293-8.

67. Yamagishi S, Matsui T, Nakamura K, Inoue H, Takeuchi M, Ueda S, et al. Olmesartan blocks inflammatory reactions in endothelial cells evoked by advanced glycation end products by suppressing generation of reactive oxygen species. Ophthalmic Res. 2008;40:10-5.

68. Niiya Y, Abumiya T, Shichinohe H, Kuroda S, Kikuchi S, leko M, et al. Susceptibility of brain microvascular endothelial cells to advanced glycation end products-induced tissue factor upregulation is associated with intracellular reactive oxygen species. Brain Res. 2006;1108:179-87.

69. Inagaki Y, Yamagishi S, Okamoto T, Takeuchi M, Amano S. Pigment epithelium-derived factor prevents advanced glycation end productsinduced monocyte chemoattractant protein-1 production in microvascular endothelial cells by suppressing intracellular reactive oxygen species generation. Diabetologia. 2003:46:284-7.

70. Ishibashi Y, Matsui T, Maeda S, Higashimoto Y, Yamagishi S. Advanced glycation end products evoke endothelial cell damage by stimulating soluble dipeptidyl peptidase-4 production and its interaction with mannose 6-phosphate/insulin-like growth factor II receptor. Cardiovasc Diabetol. 2013;12:125.

71. Ishibashi Y, Matsui T, Ueda S, Fukami K, Yamagishi S. Advanced glycation end products potentiate citrated plasma-evoked oxidative and inflammatory reactions in endothelial cells by up-regulating protease-activated receptor-1 expression. Cardiovasc Diabetol. 2014;13:60.

72. Takenaka K, Yamagishi S, Matsui T, Nakamura K, Imaizumi T. Role of advanced glycation end products (AGEs) in thrombogenic abnormalities in diabetes. Curr Neurovasc Res. 2006;3:73-7.

73. Yamagishi S, Fujimori H, Yonekura H, Yamamoto Y, Yamamoto H. Advanced glycation endproducts inhibit prostacyclin production and induce plasminogen activator inhibitor-1 in human microvascular endothelial cells. Diabetologia. 1998:41:1435-41.

74. Senger DR, van de Water L, Brown LF, Nagy JA, Yeo KT, Yeo TK, et al. Vascular permeability factor in tumor biology. Cancer Metastasis Rev. 1993;12:303-24.

75. Torisu H, Ono M, Furue M, Ohmoto Y, Nakayama J, Nishioka Y, et al. Macrophage infiltration correlates with tumor stage and angiogenesis in human malignant melanoma: possible involvement of TNFalpha and IL-1alpha. Int J Cancer. 2000;85:182-8.

76. Ueno T, Toi M, Saji H, Muta M, Bando H, Kuroi K, et al. Significance of macrophage chemoattractant protein-1 in macrophage recruitment, angiogenesis, and survival in human breast cancer. Clin Cancer Res. 2000;6:3282-9.

77. Ohta M, Kitadai Y, Tanaka S, Yoshihara M, Yasui W, Mukaida N, et al. Monocyte chemoattractant protein-1 expression correlates with macrophage infiltration and tumor vascularity in human esophageal squamous cell carcinomas. Int J Cancer. 2002;102:220-4.

78. Hoshina D, Abe R, Yamagishi SI, Shimizu H. The role of PEDF in tumor growth and metastasis. Curr Mol Med. 2010;10:292-5.

79. Yamagishi S, Abe R, Inagaki Y, Nakamura K, Sugawara H, Inokuma D, et al. Minodronate, a newly developed nitrogen-containing bisphosphonate, suppresses melanoma growth and improves survival in nude mice by blocking vascular endothelial growth factor signaling. Am J Pathol. 2004;165:1865-74 
80. Chang JS, Wendt T, Qu W, Kong L, Zou YS, Schmidt AM, et al. Oxygen deprivation triggers upregulation of early growth response-1 by the receptor for advanced glycation end products. Circ Res. 2008;102:905-13

81. Hiwatashi K, Ueno S, Abeyama K, Kubo F, Sakoda M, Maruyama I, et al. A novel function of the receptor for advanced glycation end-products (RAGE) in association with tumorigenesis and tumor differentiation of HCC. Ann Surg Oncol. 2008;15:923-33.

82. Ito $R$, Ishii $Y$, Wakiyama S, Shiba H, Fujioka S, Misawa T, Ishida Y, Hano H, Yanaga K: Prognostic significance of receptor for advanced glycation end products expression in hepatocellular carcinoma after hepatectomy. J Surg Res 2014, doi: 10.1016/j.jss.2014.06.028

83. Yaser AM, Huang Y, Zhou RR, Hu GS, Xiao MF, Huang ZB, et al. The role of receptor for advanced glycation end products (RAGE) in the proliferation of hepatocellular carcinoma. Int J Mol Sci. 2012;13:5982-9597.

84. Gong W, Wang ZY, Chen GX, Liu YQ, Gu XY, Liu WW. Invasion potential of $\mathrm{H} 22$ hepatocarcinoma cells is increased by HMGB1-induced tumor NF-KB signaling via initiation of HSP70. Oncol Rep. 2013;30:1249-56.

85. Cheng P, Dai W, Wang F, Lu J, Shen M, Chen K, et al. Ethyl pyruvate inhibits proliferation and induces apoptosis of hepatocellular carcinoma via regulation of the HMGB1-RAGE and AKT pathways. Biochem Biophys Res Commun. 2014:443:1162-8.

86. Yan W, Chang Y, Liang X, Cardinal JS, Huang H, Thorne SH, et al. High-mobility group box 1 activates caspase-1 and promotes hepatocellular carcinoma invasiveness and metastases. Hepatology. 2012;55:1863-75.

\section{Submit your next manuscript to BioMed Central and take full advantage of:}

- Convenient online submission

- Thorough peer review

- No space constraints or color figure charges

- Immediate publication on acceptance

- Inclusion in PubMed, CAS, Scopus and Google Scholar

- Research which is freely available for redistribution 